\title{
Dynamical analysis of wind turbine blades based on harmonic response
}

\author{
Qiong Wang ${ }^{1}$, Xuejun $\mathrm{Li}^{2}$, Kexiang Wei ${ }^{3}$, Mian Jiang ${ }^{4}$ \\ ${ }_{1,2,4}$ Hunan Provincial Key Laboratory of Health Maintenance for Mechanical Equipment, \\ Hunan University of Science and Technology, Xiangtan, 411201, China \\ ${ }^{1,3}$ Hunan Provincial Engineering Laboratory of Wind Power Operation, Maintenance and Testing, \\ Hunan Institute of Engineering, Xiangtan, 411104, China \\ ${ }^{3}$ Corresponding author \\ E-mail: ${ }^{1}$ wq279417262@163.com, ${ }^{2}$ hnkjdxlxj@163.com, ${ }^{3}$ kxwei@hnie.edu.cn, ${ }^{4}$ mjiang@cvm.ac.cn
}

Received 8 September 2018; received in revised form 12 February 2019; accepted 23 February 2019 DOI https://doi.org/10.21595/jve.2019.20203

Check for updates

Copyright (C) 2019 Qiong Wang, et al. This is an open access article distributed under the Creative Commons Attribution License, which permits unrestricted use, distribution, and reproduction in any medium, provided the original work is properly cited.

\begin{abstract}
As the forces applied on the wind turbine blade are irregular, the deformation and concentrated stress of the blade may vary with the load and excitation. And the lamination of composite materials is critical to blade design, it directly affects the performance and power of wind power plants. In this paper, the response characteristics of the wind turbine blade is analyzed by the application of the harmonic response method under different ply angles. Through the simulation results, the performance of the actual blade is estimated, and the rationality of this design is judged. The results demonstrate that the blade displacement response amplitude is the minimum when ply angle is $45^{\circ}$. It is also found that the maximum displacement response occurs in the $Y$ direction (i.e. parallel to the flow direction) by analyzing the displacement of each section in the blade, while the maximum stress is located at blade root.
\end{abstract}

Keywords: wind turbine blade, harmonic response analysis, dynamic response, ply angle.

\section{Introduction}

A wind turbine blade is a hollow composite structure, and it is manufactured from composite materials. Blade is one of the most important structural components of the wind turbine, the force of the blade is complex, and it is affected by aerodynamic force, elastic force and inertial force during the rotation process [1]. As the power of large wind turbines continues to increase, the length and flexibility of wind turbine blades continue to increase, and the blades are prone to vibration. Large amplitude vibrations can cause large dynamic stresses and accelerate the fatigue of the blade material, and even cause blade breakage. Therefore, the analysis of the static structure of the blade should be considered in the analysis, as well as the dynamic response of the blade $[2,3]$. The research of its vibration characteristics has become the focus of wind turbine development.

Wind turbine blades are usually made by fiber reinforced plastic (FRP). Its specific production process determines the performance. The lamination of composite materials is critical to blade design, it directly affects the performance and power of wind power plants, and also determines the cost of wind power. In order to ensure the structural safety of the blade, in the design of the blade, it is necessary to calculate the maximum load of each section of the blade under load conditions and check the strength of the blade section layup material under this load. The three key parameters of the composite layup are the ply angle, the ply thickness and the ply order [4,5]. Hayat and $\mathrm{Ha}[6]$ studied of unbalanced tri-axial non-crimp fabrics laminates typically used in the blade skin layup. They found that the highest bend-twist coupling up to 0.56 was achieved when all three kinds of unbalances (i.e. ply-angle, ply-material and ply-thickness unbalances) were simultaneously presented in the laminates. Albanesi et al. [7] presented a novel methodology to design wind turbine blades using the Inverse Finite Element Method. Wang et al. [8] designed a wind turbine blade made by fiber reinforced polymer composites, in which the local structural stiffness is enhanced while the local stability of the blade is improved. 
In this paper, through the simulation results, the performance of the actual blade is estimated, and the rationality of this design is judged. Considering the blade under different ply angles, its response characteristics is analyzed under the simple harmonic load of known frequency by using harmonic response method. Harmonic response is an analytical technique for analyzing the steady-state response of a structure under simple harmonic varying loads over time. The amplitude-frequency characteristic curve of the structure displacement versus frequency can be obtained by analysis [9]. The harmonic dynamic response analysis results can predict the continuous dynamic characteristics of the structure. Therefore, it can be judged whether the design can overcome the harmful effects caused by resonance, fatigue and other forced vibrations. And ply parameters have a significant effect on the performance of blades [10, 11]. Using the above method, the effects of different ply angles on the vibration displacement are studied, and the dynamic response characteristics of the blade structure in the optimal ply mode are obtained.

\section{Dynamic equation of harmonic response analysis}

The dynamic equation of linear system vibration [12] is:

$[M]\{\ddot{u}\}+[C]\{\dot{u}\}+[K]\{u\}=\sum_{k=1}^{N}\left\{F_{k} e^{i \omega_{k} t}\right\}$,

where, $[M]$ is the mass matrix, $[C]$ is the damping matrix, and $[K]$ is the stiffness matrix, $\{\ddot{u}\},\{\dot{u}\}$, $\{u\}$ is the node acceleration vector, velocity vector, and displacement vector. $F_{k}$ is the complex excitation force vector.

Initial displacement $\{u(0)\}$ and speed $\{\dot{u}(0)\}$ are expressed as:

$\{u(0)\}=\left\{u_{0}\right\}, \quad\{\dot{u}(0)\}=\left\{\dot{u}_{0}\right\}$,

where, $u_{0}$ and $\dot{u}_{0}$ are abbreviated initial displacement and initial velocity.

According to the characteristics of harmonic response analysis, Since the incentive is simple, so, the steady-state vibration of the system is also a simple harmonic vibration. So:

$\left\{u_{k}\right\}=\left(\left\{v_{k}\right\}+i\left\{w_{k}\right\}\right) e^{i \omega_{k} t}$,

where, $u_{k}$ is the displacement response of the $k$ th excitation, $v_{k}$ and $w_{k}$ are the real and imaginary parts of $u_{k}$.

Substituting Eq. (3) into (1), the kinetic equation corresponding to the $k$ th excitation force is:

$\left(-\omega_{k}^{2}[M]+i \omega_{k}[C]+[K]\right)\left(\left\{v_{k}\right\}+i\left\{w_{k}\right\}\right)=\left(\left\{A_{k}\right\}+i\left\{B_{k}\right\}\right), \quad(k=1,2,3, \ldots, N)$.

In order to decouple the dynamic Eq. (1) represented by the physical coordinates, it must be converted to a modal coordinate system, so the equation is expressed as [11]:

$M_{r}\left\{\ddot{\eta}_{r k}(t)\right\}+2 M_{r} \omega_{0 r} \xi_{r}\left\{\dot{\eta}_{r k}(t)\right\}+\omega_{0 r}^{2} M_{r}\left\{\eta_{r k}(t)\right\}=F_{r k}(t)$,

where, $M_{r},\left\{\eta_{r k}(t)\right\}, F_{r k}(t)$ are the main mass corresponding to the $r$ th mode, and the main coordinate and the exciting force of the $r$ th mode under the $k$ th excitation, $\omega_{0 r}$ is the circular frequency of the $r$ th mode, $\xi_{r}$ is the damping ratio.

The initial displacement and velocity in modal coordinates are:

$\{\eta(0)\}=\left\{\eta_{0}\right\}, \quad\{\dot{\eta}(0)\}=\left\{\dot{\eta}_{0}\right\}$,

where, $\eta_{0}$ is the initial displacement in the modal coordinate system, $\dot{\eta}$ is the initial velocity in the 
modal coordinate system. In steady-state intermittent vibration, modal displacement and modal excitation can be expressed as:

$\eta_{r k}=\eta_{r c k} e^{i \omega_{k} t}, \quad r=1,2, \ldots, M, k=1,2, \ldots, N$,

$F_{r k}=F_{r c k} e^{i \omega_{k} t}, \quad r=1,2, \ldots, M, \quad k=1,2, \ldots, N$,

where, $\eta_{r c k}, F_{r c k}$ are respectively expressed as the excitation amplitude and response amplitude in the $r$ th mode.

Substituting Eqs. (7) and (8) into (5), so:

$$
\begin{aligned}
& \left(-\omega_{k}^{2} M_{r}+i 2 \omega_{0 r} \omega_{k} \xi_{r} M_{r}+\omega_{0 r}^{2} M_{r}\right) \eta_{r c k}=F_{r c k}, \\
& \eta_{r c k}=\frac{F_{r c k}}{\left(\omega_{0 r}^{2}-\omega_{k}^{2}\right) M_{r}+i 2 \omega_{0 r} \omega_{r} \xi_{r} M_{r}} .
\end{aligned}
$$

Therefore, the steady state displacement response corresponding to each mode is:

$\left\{u_{r k}\right\}=\left\{\psi_{r k}\right\} \eta_{r k}$

where, $\psi_{r k}$ is the feature vector of the $r$ th mode under the $k$ th excitation.

The steady-state displacement response corresponding to the $k$ th excitation is:

$\left\{u_{k}\right\}=\sum_{r=1}^{M}\left\{\psi_{r k}\right\} \eta_{r k}$.

According to the superposition principle of the linear system, the total steady-state displacement response corresponding to the $N$ excitations is:

$\{u\}=\sum_{k=1}^{N}\left\{u_{k}\right\}=\sum_{k=1}^{N} \sum_{r=1}^{M}\left\{\psi_{r k}\right\} \eta_{r k}$.

In the process of solving, using harmonic response analysis method to analyze the response of each harmonic excitation in this time period [13]. Then superimpose all the stimulus responses, get the total response during this time period. Finally, the harmonic response analysis method is used to solve the vibration response solutions of other time regions, get the vibration response solution over the entire area [14].

The frequency range of the harmonic response analysis is mainly based on the natural frequency of the blade. From the modal analysis, calculating the frequency range of $0-20 \mathrm{~Hz}$, and the response value of the blade is calculated every $0.2 \mathrm{~Hz}$.

\section{Simulation analysis of harmonic response of wind turbine blades}

Using the 3D software solid works to build a 3D model of the wind turbine blade, and through the ANSYS composite module to achieve the layering design of the blade, Then, the dynamic stress analysis is carried out by harmonic response analysis method to calculate the displacement and stress of the structure.

\subsection{Blade model}

In this paper, taking a $2 \mathrm{MW}$ wind turbine blade as an example, its design parameters are given as shown in Table 1 . The wind speed is set to $11 \mathrm{~m} / \mathrm{s}$, and the rated speed of the blade is $19 \mathrm{r} / \mathrm{min}[15]$. 
Table 1. The design parameters of a $2 \mathrm{MW}$ wind turbine blade

\begin{tabular}{|c|c|}
\hline Power $(\mathrm{MW})$ & 2 \\
\hline Diameter(m) & 84 \\
\hline The number of blades & 3 \\
\hline Blade speed range (rpm) & $6.5-25$ \\
\hline Rated speed (rpm) & 19 \\
\hline The rated wind speed (m/s) & 11 \\
\hline
\end{tabular}

\subsection{Finite element analysis of blades by ANSYS}

According to the chord length and torsion angle values in different cross-section of the blade, a three-dimensional model may be established. And importing it into ANSYS to get the finite element model. as shown in Fig. 1.

The material glass steel is chosen for blade, and material properties are shown in Table 2.

Table 2. Material properties of blade

\begin{tabular}{|c|c|c|c|c|}
\hline$E_{1}(\mathrm{GPa})$ & $E_{2}(\mathrm{GPa})$ & $G(\mathrm{GPa})$ & $\mu$ & $p\left(\mathrm{~kg} / \mathrm{m}^{3}\right)$ \\
\hline 62.5 & 16.5 & 5.5 & 0.2 & 1.7 \\
\hline
\end{tabular}

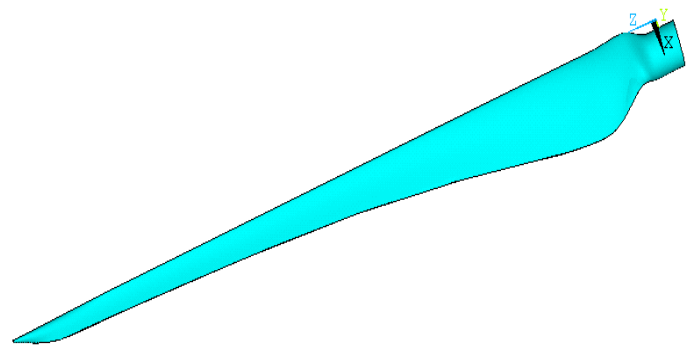

a)

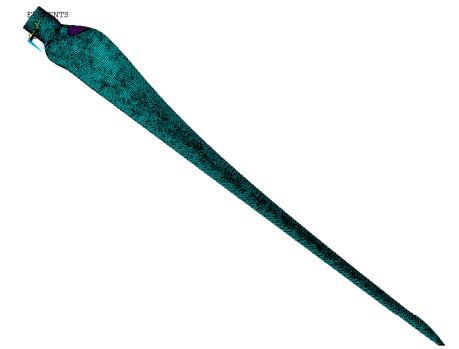

b)

Fig. 1. Model of the wind turbine blade

The SHELL181 unit is used in the finite element analysis of the blade. The SHELL181 unit section definition uses "shell section". The cell section is defined as shown in Fig. 2 and Fig. 3.

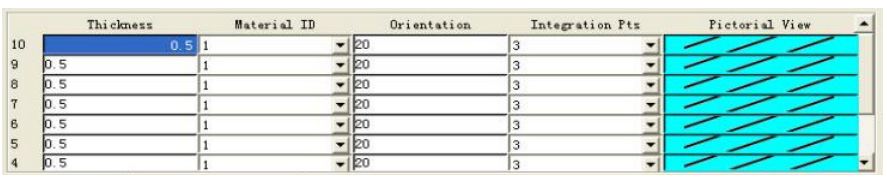

Fig. 2. SHELL181 unit section definition

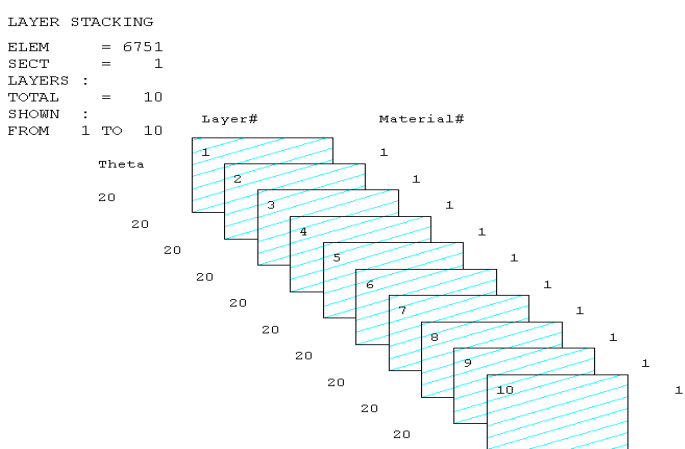

Fig. 3. The display of blade's layer

The root of the blade is embedded in the hub, in the course of the analysis, it is assumed that 
the root portion is fixed, so that a fixed constraint of displacement is applied to the three directions of the blade root.

\subsubsection{Effects of ply angles on the harmonic response}

In this study, six cases where the ply angles are $-45^{\circ}, 0^{\circ}, 20^{\circ}, 45^{\circ}, 60^{\circ}$ and $90^{\circ}$ are selected. A coordinate system on the blade should first be created, in which the $Z$-axis is the direction along the length of the blade, the $Y$-axis direction is the direction along the chord length, and the $X$-axis direction is perpendicular to the chord length. We divide the blade into 21 sections and discuss the displacement response of the first, the eighth, the sixteenth and the twenty-first section. The relationship between the displacement response and the frequency in $X, Y, Z$ direction are shown in Fig. 4, Fig. 5 and Fig. 6, respectively.

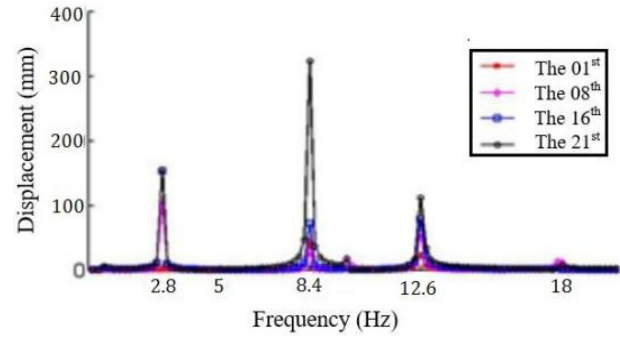

a) Displacement response at $-45^{\circ}$ ply angles

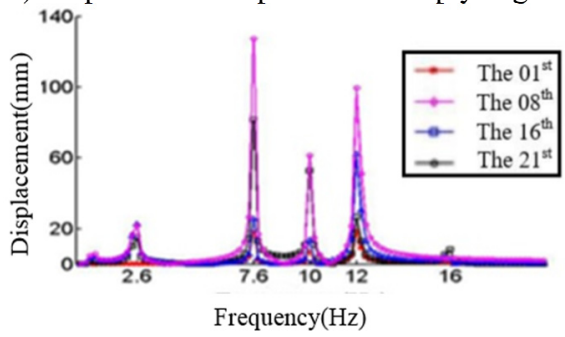

c) Displacement response at $20^{\circ}$ ply angles

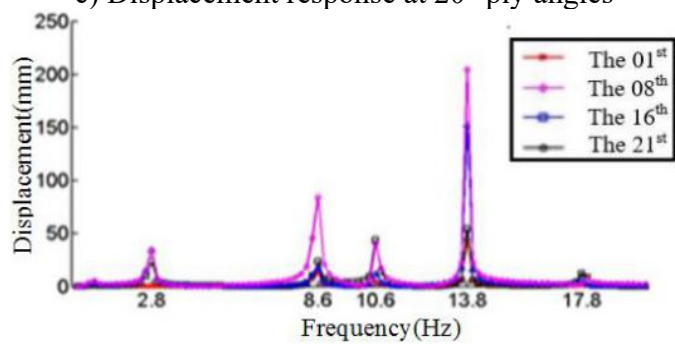

e) Displacement response at $60^{\circ}$ ply angles

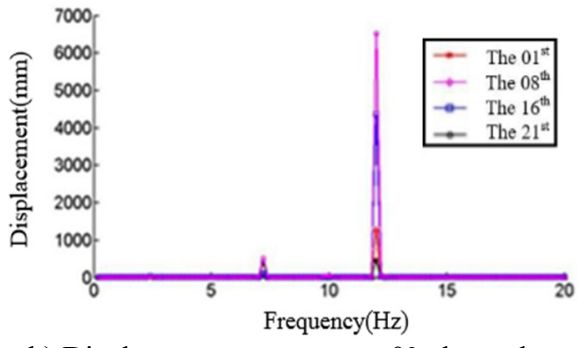

b) Displacement response at $0^{\circ}$ ply angles

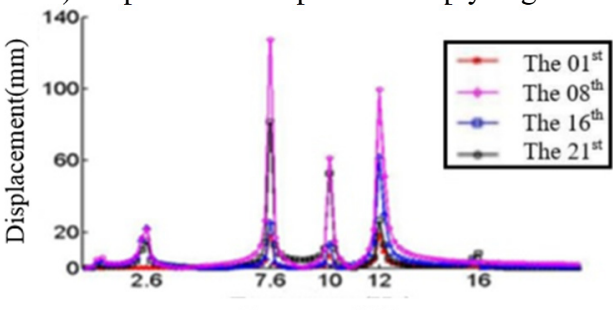

Frequency $(\mathrm{Hz})$

d) Displacement response at $45^{\circ}$ ply angles

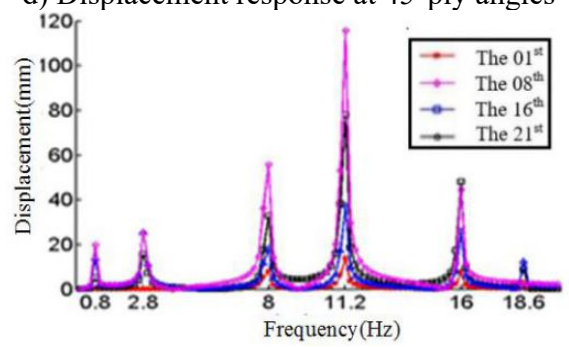

f) Displacement response at $90^{\circ}$ ply angles

Fig. 4. Relationship between the displacement and frequency in $X$ direction

Fig. 4 shows that each section of the blade has a plurality of displacement response peaks at different ply angles, and the displacement peak of the different cross-section corresponding to the same frequency. When the ply angle is $0^{\circ}$, the peak of the displacement response is several times than others. The displacement peak at $-45^{\circ}, 20^{\circ}$ and $60^{\circ}$ is higher than that at $45^{\circ}$ and $90^{\circ}$, at same time, the response peaks at $90^{\circ}$ ply angle appear at $0.8 \mathrm{~Hz}, 2.8 \mathrm{~Hz}, 8 \mathrm{~Hz}, 11.2 \mathrm{~Hz}, 16 \mathrm{~Hz}$ and $18.6 \mathrm{~Hz}$, respectively, in which the blades would be no resonance. The first four orders natural frequencies of the blade are less than $2.8 \mathrm{~Hz}$, and the displacement response peak occurs twice when the frequency is less than $2.8 \mathrm{~Hz}$ at $90^{\circ}$ ply angle. So, the blade performance in the $X$ direction is optimal when the ply angle is $45^{\circ}$. 


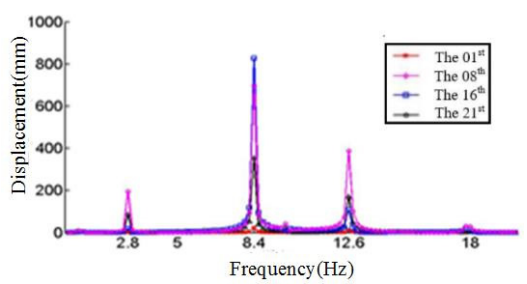

a) Displacement response at $-45^{\circ}$ ply angles

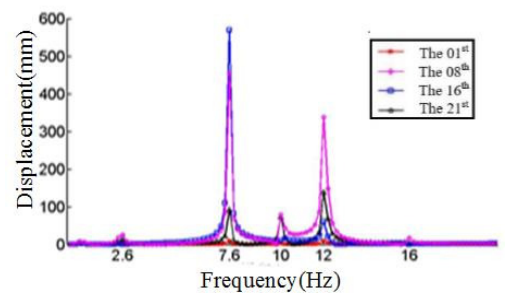

c) Displacement response at $20^{\circ}$ ply angles

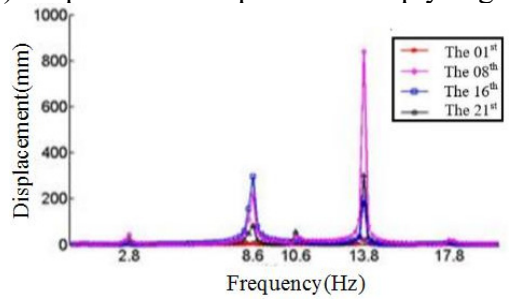

e) Displacement response at $60^{\circ}$ ply angles

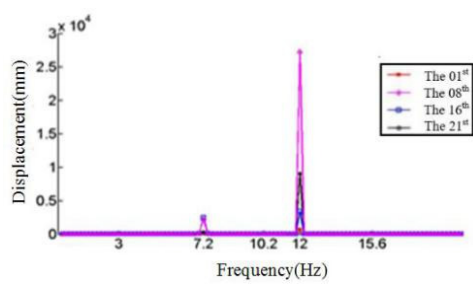

b) Displacement response at $0^{\circ}$ ply angles

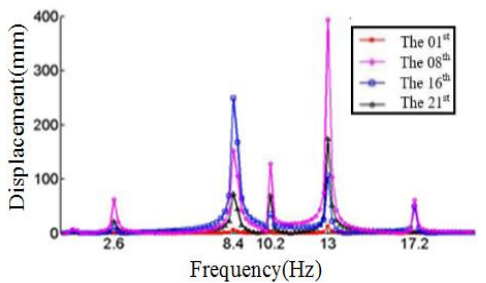

d) Displacement response at $45^{\circ}$ ply angles

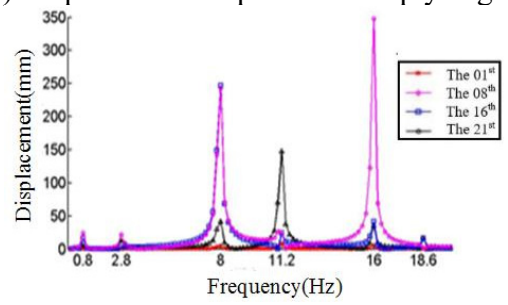

f) Displacement response at $90^{\circ}$ ply angles

Fig. 5. Relationship between the displacement and frequency in $Y$ direction

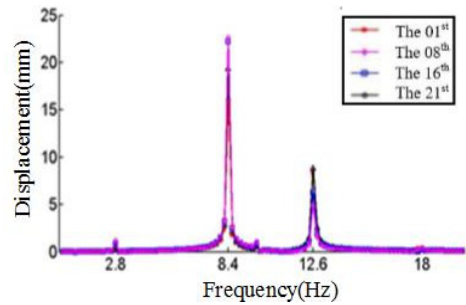

a) Displacement response at $-45^{\circ}$ ply angles

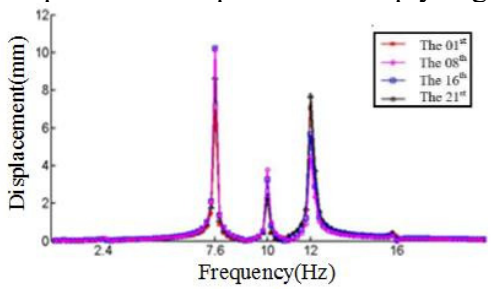

c) Displacement response at $20^{\circ}$ ply angles

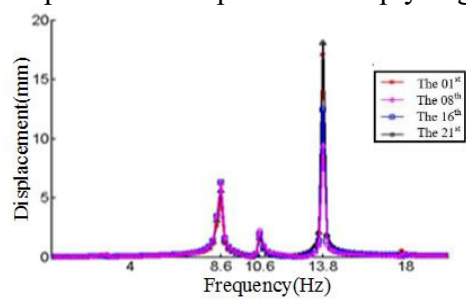

e) Displacement response at $60^{\circ}$ ply angles

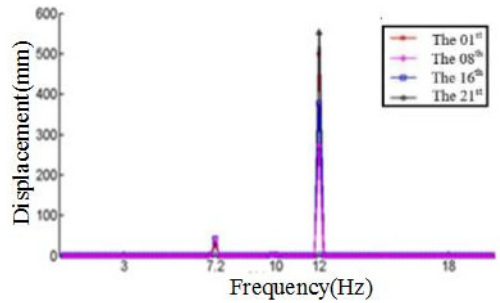

b) Displacement response at $0^{\circ}$ ply angles

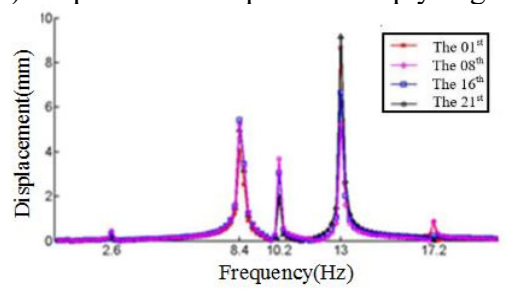

d) Displacement response at $45^{\circ}$ ply angles

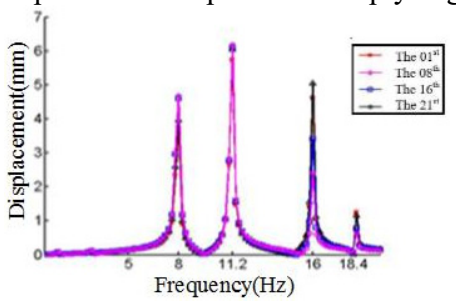

f) Displacement response at $90^{\circ}$ ply angles

Fig. 6. Relationship between the displacement and frequency in $Z$ direction 
Comparing Fig. 4, Fig. 5 and Fig. 6, it can be found that the displacement peaks of the blade in the $X, Y$ and $Z$ direction have the same frequency at same ply angle, and the largest displacement response in three directions occurred at $0^{\circ}$ ply angle. When the ply angle is $45^{\circ}$ and $90^{\circ}$, the displacement response peak is relatively small. For all three directions, there is no frequent occurrence of low-frequency displacement response peak at $45^{\circ}$ ply angle, and the peak of the displacement response is ideal.

\subsubsection{Displacement analysis at $45^{\circ}$ ply angle}

The displacement response for each section is analyzed when the ply angle is set to $45^{\circ}$. The displacement response peak is mainly considered at frequency $2.6 \mathrm{~Hz}, 8.4 \mathrm{~Hz}, 10.2 \mathrm{~Hz}, 13 \mathrm{~Hz}$ and $16.2 \mathrm{~Hz}$, respectively. In particular, the largest displacement response in the $X, Y$ and $Z$ directions are analyzed.

The response in the $X$ direction and the corresponding section are shown in Table 3. From Table 4, it can be seen that the displacement response of the blade in the $X$ direction has the following characteristics: (a) the maximum response for all frequencies is located at blade tip except $16.2 \mathrm{~Hz}$; (b) the maximum displacement response of the blade is the largest when the frequency is $13 \mathrm{~Hz}$; (c) the 10th order natural frequency of the blade is higher than $16.2 \mathrm{~Hz}$, so the deformation will be relatively large when the frequency is $16.2 \mathrm{~Hz}$, and the blade will appear to reverse and shimmy coupling deformation, so the maximum deformation of the location is different from others.

Table 3. The maximum response in the $X$ direction and the corresponding section

\begin{tabular}{|c|c|c|c|c|}
\hline $\begin{array}{c}\text { Frequency } \\
(\mathrm{Hz})\end{array}$ & $\begin{array}{c}\text { The section of the } \\
\text { maximum } \\
\text { displacement }\end{array}$ & $\begin{array}{c}\text { Displacement } \\
\text { maximum }(\mathrm{mm})\end{array}$ & $\begin{array}{c}\text { The section of the } \\
\text { minimum } \\
\text { displacement }\end{array}$ & $\begin{array}{c}\text { Displacement } \\
\text { minimum (mm) }\end{array}$ \\
\hline 2.6 & 21 & 46.71 & 1 & 0.28 \\
\hline 8.4 & 21 & 71.51 & 4 & 10 \\
\hline 10.2 & 21 & 56.26 & 15 & 0.82 \\
\hline 13 & 21 & 119.3 & 12 & 3.16 \\
\hline 16.2 & 5 & 79.14 & 17 & 0.21 \\
\hline
\end{tabular}

Table 4. The maximum response in the $Y$ direction and the corresponding section

\begin{tabular}{|c|c|c|c|c|}
\hline $\begin{array}{c}\text { Frequency } \\
(\mathrm{Hz})\end{array}$ & $\begin{array}{c}\text { The section of the } \\
\text { maximum } \\
\text { displacement }\end{array}$ & $\begin{array}{c}\text { Displacement } \\
\text { maximum }(\mathrm{mm})\end{array}$ & $\begin{array}{c}\text { The section of the } \\
\text { minimum } \\
\text { displacement }\end{array}$ & $\begin{array}{c}\text { Displacement } \\
\text { minimum }(\mathrm{mm})\end{array}$ \\
\hline 2.6 & 21 & 62.15 & 1 & 0.2 \\
\hline 8.4 & 16 & 248.8 & 1 & 5.76 \\
\hline 10.2 & 21 & 128.3 & 1 & 2.92 \\
\hline 13 & 21 & 394.1 & 12 & 3.16 \\
\hline 16.2 & 18 & 93.2 & 14 & 0.13 \\
\hline
\end{tabular}

Table 4 shows the displacement response of the blade in the $Y$ direction. It is obviously observed in Table 3 that: (a) the displacement response at $13 \mathrm{~Hz}$ is the largest; (b) the largest response is all located at the end of the blade for all frequencies; (c) the minimum displacement at $2.6 \mathrm{~Hz}, 8.4 \mathrm{~Hz}$ and $10.2 \mathrm{~Hz}$ occur at the first cross section (i.e., the root of the blade).

As the $Z$ direction is the length of the blade, the variation of vibration response amplitude is small. Then the displacement response is relatively simple. In $Z$ direction, the displacement peaks only appeared at $2.6 \mathrm{~Hz}, 8.4 \mathrm{~Hz}, 10.2 \mathrm{~Hz}$ and $13 \mathrm{~Hz}$. The corresponding displacement data of the blade is shown in Table 5.

Comparing Table 3, Table 4 and Table 5, it can be seen that the maximum displacement response peak usually occurs in the $Y$ and $X$ direction. As the response in the $Z$ direction is the smallest, the displacement in the $Z$-axis direction is negligible. For all frequencies, the maximum 
displacement responses are located at the tip of the blade, and the displacement response of the blade tip is increasing with the increase of the frequency, that is, the vibration amplitude of the blade tip is increasing.

Table 5. The maximum response in the $Z$ direction and the corresponding section

\begin{tabular}{|c|c|c|c|c|}
\hline $\begin{array}{c}\text { Frequency } \\
(\mathrm{Hz})\end{array}$ & $\begin{array}{c}\text { The section of the } \\
\text { maximum } \\
\text { displacement }\end{array}$ & $\begin{array}{c}\text { Displacement } \\
\text { maximum }(\mathrm{mm})\end{array}$ & $\begin{array}{c}\text { The section of the } \\
\text { minimum } \\
\text { displacement }\end{array}$ & $\begin{array}{c}\text { Displacement } \\
\text { minimum (mm) }\end{array}$ \\
\hline 2.6 & 21 & 0.44 & 1 & 0.15 \\
\hline 8.4 & 13 & 5.5 & 1 & 4.05 \\
\hline 10.2 & 21 & 3.68 & 2 & 1.2 \\
\hline 13 & 7 & 9.21 & 21 & 5.22 \\
\hline
\end{tabular}

\section{Conclusions}

The application of the harmonic response method to analyze the vibration characteristics of a 2 MW blade under different ply angle has been presented. The study demonstrates that the ply parameters have a significant effect on the vibration response performance of the blade. The displacement peaks of the blade in the $X, Y$ and $Z$ direction have the same frequency at same ply angle, and the largest displacement response in three directions occurred at $0^{\circ}$ ply angle. For all three directions, there is no frequent occurrence of low-frequency displacement response peak at $45^{\circ}$ ply angle, and the peak of the displacement response is ideal. For all frequencies, the maximum displacement responses are located at the tip of the blade, and the displacement response of the blade tip is increasing with the increase of the frequency.

Harmonic response analysis can determine whether the design can overcome the harmful effects caused by resonance, fatigue and other forced vibrations, and improve the blade structure. (1) When the blade's ply angle is $45^{\circ}$, the aerodynamic performance of the blade is optimal. (2) The vibration displacement at the tip of the blade is the largest, which is easy to cause the blade to break. Therefore, the airfoil at the tip of the blade should be improved. In subsequent analysis blade model will be improved, and the aerodynamic performance of the blade when it is loaded will be analyzed.

\section{Acknowledgements}

This work was partly supported by the National Natural Science Foundation of China (Grant No. 11472103, 11572125 and 51775182) and Hunan Provincial Department of Education Research Project (Grant No. 17C0398).

\section{References}

[1] Monte A. D., Betta S. D., Castelli M. R., Benini E. Proposal for a coupled aerodynamic-structural wind turbine blade optimization. Composite Structures, Vol. 159, Issue 3, 2017, p. 144-156.

[2] Johnson D. A., Gu M., Gaunt B. Wind turbine performance in controlled conditions: BEM modeling and comparison with experimental results. International Journal of Rotating Machinery, Vol. 23, Issue 5, 2016, p. 5460823.

[3] Fagan E. M., Flanagan M., Leen S. B., et al. Physical experimental static testing and structural design optimization for a composite wind turbine blade. Composite Structures, Vol. 164, Issue 32, 2017, p. 90-103.

[4] Kulkarni P. A., Hu W., Dhoble A. S., Padole P. M. Statistical wind prediction and fatigue analysis for horizontal-axis wind turbine composite material blade under dynamic loads. Advances in Mechanical Engineering, Vol. 9, Issue 9, 2017, https://doi.org/10.1177/1687814017724088.

[5] Asl M. E., Niezrecki C., Sherwood J., Avitabile P. Similitude analysis of thin-walled composite I-beams for subcomponent testing of wind turbine blades. Wind Engineering, Vol. 41, Issue 5, 2017, p. 297-312. 
[6] Hayat K., Ha S. K. Load mitigation of wind turbine blade by aeroelastic tailoring via unbalanced laminates composites. Composite Structures, Vol. 128, Issue 3, 2015, p. 122-133.

[7] Albanesi A., Fachinotti V., Peralta I., Storti B., Gebhardt C. Application of the inverse finite element method to design wind turbine blades. Composite Structures, Vol. 161, Issue 25, 2017, p. $160-172$.

[8] Wang Y. J., Zhu S. R., Wang J. J. The ply optimum design of composites wind turbine blade based on the local stability. Advanced Materials Research, Vol. 988, 2014, p. 445-448.

[9] Gangele A., Ahmed S. Modal analysis of S809 wind turbine blade considering different geometrical and material parameters. Journal of The Institution of Engineers, Vol. 94, Issue 3, 2013, p. 225-228.

[10] Philippe M., Babarit A., Ferrant P. Modes of response of an offshore wind turbine with directional wind and waves. Renewable Energy, Vol. 49, Issue 1, 2013, p. 151-155.

[11] Tran T. T., Kim D. H. A CFD study into the influence of unsteady aerodynamic interference on wind turbine surge motion. Renewable Energy, Vol. 90, Issue 3, 2016, p. 204-228.

[12] Huang X. D., Hse C. Y., Shupe T. F. Evaluation of the performance of the composite bamboo/epoxy laminated material for wind turbine blades technology. Bioresources, Vol. 10, Issue 1, 2015, p. 660-671.

[13] Bagherpoor T., Li X. Structural optimization design of 2MW composite wind turbine blade. Energy Procedia, Vol. 105, Issue 2, 2017, p. 1226-1233.

[14] Rocha I. B. C. M., Raijmaekers S., Nijssen R., et al. Hygrothermal ageing behaviour of a glass/epoxy composite used in wind turbine blades. Composite Structures, Vol. 174, Issue 13, 2017, p. 110-122.

[15] Lu En, Li Wei, Yang Xuefeng, Wang Yuqiao, Liu Yufei Dynamic modeling and analysis of a rotating piezoelectric smart beam. International Journal of Structural Stability and Dynamics, Vol. 18, Issue 1, 2018, p. 1850003.

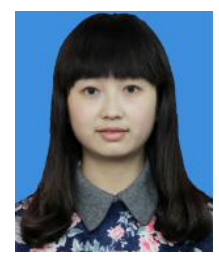

Wang Qiong received Master's degree in power engineering from Hunan Institute of Engineering, Xiantan, China, in 2015. Now she works at Hunan Institute of Engineering. She current research interests include dynamics and fault diagnosis.

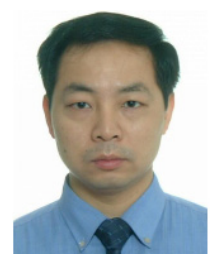

Xuejun Li received his Ph.D. degree in Mechanical Engineering from Central South University, Changsha, China, in 2003. Now he is a Professor in Hunan University of Science and Technology. His main research interests include mechanical dynamics and fault diagnosis.

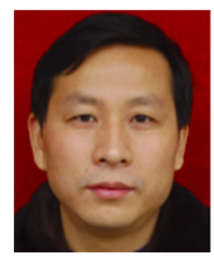

Kexiang Wei is Professor of mechanical engineering at Hunan Institute of Engineering. He received his Ph.D. degree from Shanghai Jiaotong University (SJTU) in 2006. In the following two years, he held a position as a postdoctoral at SJTU. Dr. Wei was invited to the University of Sydney as a visiting scholar in 2010. His research fields include smart materials and vibration control. He has published more than 40 papers including $10 \mathrm{SCI}$ papers and 30 EI papers.

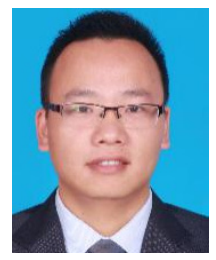

Mian Jiang received Ph.D. degree in mechanical engineering from Central South University, Changsha, China, in 2012. Now he is an Associate Professor in Hunan University of Science and Technology. His current research interests include nonlinear dynamics and fault diagnosis. 